\title{
OS PRIMÓRDIOS DE GRAMSCI: ENTRE O RISORGIMENTO E A I GUERRA MUNDIAL*
}

\author{
DOMENICO LOSURDO ${ }^{* *}$
}

\begin{abstract}
RESUMO: O presente texto analisa as influências do pensamento liberal sobre os primórdios da formação intelectual e política de Gramsci. Mostra que, inicialmente, Gramsci encontra em Benedetto Croce e Giovanni Gentile, representantes do neo-idealismo italiano, um referencial de análise mais progressista e moderno sobre a Itália do que o de Guglielmo Ferrero e Filippo Turati, expoentes do Partido Socialista Italiano. Sua posição em favor do liberalismo manifesta-se na defesa da modernidade e da capacidade de autodeterminação do sujeito. Contudo, a influência liberal não o impediu de saudar a revolução de outubro de 1917, quando ainda permaneciam pontos de contato entre seu pensamento e o de Croce. A passagem de Gramsci ao comunismo e sua ruptura com a influência neo-idealista e liberal ocorrerão durante o aprofundamento dos conflitos históricos, tais como a I Guerra Mundial e o crescimento do antagonismo entre o Ocidente liberal e a Revolução Soviética.
\end{abstract}

Palavras-chave: Gramsci. Liberalismo. Neo-idealismo. Partido Socialista Italiano.

\section{THE BEGINNING OF GRAMSCI: BETWEEN THE RISORGIMENTO AND WORLD WAR I}

ABSTRACT: The text analyzes the influence of liberal thinking in the beginning of Gramsci's intellectual and political development. It shows that initially Gramsci finds in the ideas of Benedetto Croce and Giovanni Gentile, supporters of Italian new-idealism, a more

* O presente texto refere-se ao primeiro capítulo do livro de Domenico Losurdo, Antonio Gramsci, dal liberalismo al "comunismo critico" (Roma: Gamberetti, 1997), traduzido por Teresa Ottoni e gentilmente cedido pela Editora Revan, para o qual elaboramos um resumo e uma pequena introdução.

** Doutor em Filosofia e professor de Filosofia e Sociologia da Universidade de Estudos de Urbino (Itália).E-mail: d.losurdo@uniurb.it 
progressive and modern framework for examining Italy than in the ideas defended by Guglielmo Ferrero e Filippo Turati, exponents of the Italian Socialist Party. His support of liberalism manifests itself in the defense of modernity and the capacity for self-determination. But the liberal influence did not stop him from welcoming the october Revolution of 1917, although there still remained points of contact between Croce's thinking and his own. Gramsci's embrace of communism and his rupture with new-idealist and liberal trends takes place later, during the deepening of historical conflicts, such as Word War I and the increasing antagonism between the liberal West and the Soviet Revolution.

Key words: Gramsci. Liberalism. New-idealism. Italian Socialist Party.

\section{Introdução}

A formação inicial de Gramsci foi liberal. A filosofia dos dois maiores expoentes do neo-idealismo e do liberalismo, Benedetto Croce e Giovanni Gentile, constituiu o seu referencial teórico para analisar a Itália moderna e não as idéias positivistas e naturalistas de Guglielmo Ferrero e Filippo Turati, representantes do Partido Socialista Italiano. Gramsci relaciona os dois filósofos neo-idealistas ao Ressurgimento, um processo que trouxe a modernização para a Itália; um movimento que criou o Estado moderno e colaborou para a destruição do Estado clerical. Ao assumir um posicionamento contra o Syllabus (1864), documento da igreja católica que condena a liberdade de consciência e de expressão, a igualdade jurídica e a obrigatoriedade escolar, Gramsci aproxima-se do mundo e da liberdade dos modernos. A igreja católica condena Hegel, enquanto Gramsci defende o pensamento hegeliano e seus principais representantes na Itália, Croce e Gentile, os quais eram, antes do fascismo, os defensores de um pensamento liberal.

Já a cultura do Partido Socialista, eivada de positivismo, não contribuía para compreender os problemas da Itália, especialmente a questão meridional, e nem para resolvê-los. Os representantes daquele Partido, tais como Guglielmo Ferrero e Filippo Turati, faziam uma leitura naturalista e até racial dos meridionais, tidos como "poltrões, incapazes, criminosos, bárbaros". Desde a época do liceu, partilhando do sofrimento de seu povo, Gramsci rejeitara esse tipo de estigma e, com razão, considera superior, no plano político e filosófico, a cultura neo-idealista. Esta, ao enfrentar o pro- 
blema do atraso do Mezzogiorno, apesar de não vinculá-lo ao sistema capitalista, recusa-se a abandonar o terreno da história.

A cultura neo-idealista também se mostra superior à do Partido Socialista durante a I Guerra Mundial, uma vez que se opõe à leitura naturalista dos conflitos sociais. Quando irrompe a I Guerra Mundial, Gramsci não olha para Berlim ou para a posição assumida pelos líderes da Segunda Internacional, mas continua a voltar sua atenção, de modo privilegiado, para os dois filósofos neo-idealistas.

De certo modo, Gramsci começa a sua vida política e intelectual como liberal, embora isso não entre em contradição com o seu vivo interesse por Marx, cuja interpretação é mediada pela leitura de Croce e Gentile. Também a esses dois filósofos neo-idealistas se devem as duras manifestaçóes de Gramsci contra o jacobinismo, que chegou a caracterizar como visão messiânica, incapaz de "compreender a história".

Suas ligaçôes com a mais avançada cultura liberal da época não o impediram, contudo, de saudar a Revolução de Outubro de 1917. Se tinha em Hegel uma referência contra o Syllabus, passou a defender Lênin contra este documento. A revolução bolchevique é compreendida como uma conseqüente aplicação dos princípios liberais.

Contudo, a adesão à Revolução Soviética não representou ainda uma imediata ruptura de Gramsci com Croce e Gentile. Foi a partir de dramáticos acontecimentos históricos do início do século XX que se aprofundou e radicalizou a crítica de Gramsci ao liberalismo, amadurecendo sua passagem ao comunismo.

\section{O encontro com Croce e Gentile}

Quando irrompe a I Guerra Mundial, momento de virada na história do século XX, Gramsci tem 23 anos. Filiado ao Partido Socialista o que não se sabe ao certo -, não se envolve com particular intensidade na atividade política (Fiori, 1966, p. 96 e 107). Dentre todos os que já são ou estão destinados a se tornar dirigentes de primeiro plano do movimento operário internacional, o provinciano vindo da Sardenha distingue-se pelo fato de não ter na bagagem os debates teóricos e políticos próprios da II Internacional. Evidentemente, já é clara sua ligação com as classes subalternas, soldada pela modesta origem social, pela experiência dolorosa das privações cotidianas, por uma sensibilidade e seriedade 
moral que alimentam ainda mais a atitude empática em relação aos que são submetidos a uma vida de sofrimentos. E são muitos na Sardenha, onde, junto ao analfabetismo, grassam a malária, o tracoma, a tuberculose e a inanição.

Contudo, a empatia de Gramsci em relação às classes e aos povos mantidos em condição subalterna não está confinada à sua ilha de origem. Os trabalhos escolares testemunham a sua plena identificação com "os infelizes povos das colônias", rotulados e tratados como "bárbaros" e "incivilizados" pelas periódicas "cruzadas" da "velha Europa". Porém, no plano propriamente cultural, quem suscita a atenção participativa do estudante sardo são principalmente Croce e Salvemini (Fiori, 1966, p. 66 e 78). Chegando à universidade, em Turim, a cidade que é ou está para se tornar o centro do movimento operário e socialista, o jovem Gramsci continua a freqüentar professores de orientação liberal (Luigi Einaudi, Francesco Ruffini, Gioele Solari) que, também, são profundamente influenciados pelo filósofo liberal Benedetto Croce (idem, ibid., p. 86 e 87). O próprio Salvemini, que vimos merecer a atenção do jovem sardo, apesar de nutrir alguma simpatia pelo "movimento proletário", estava empenhado em uma batalha fundamentalmente liberal contra o protecionismo e qualquer forma de "intervencionismo estatal"; no plano teórico, considerava-se discípulo de Adam Smith, muito mais do que de Karl Marx. Bastante raras, no Gramsci desses anos, são as referências, diretas ou indiretas, a Antonio Labriola (idem, ibid., p. 108). ${ }^{1}$

São unânimes os testemunhos relativos à influência de Croce e, sucessivamente, também de Gentile sobre o estudante sardo e sobre o universitário turinês. Mas seria um erro reduzir essa influência a uma experiência acadêmica ou abstratamente cultural. O encontro com os dois filósofos não é o dado originário do qual derivar, com certa variação, o posterior desenvolvimento do pensamento de Gramsci; esse encontro é ele mesmo um resultado, na medida em que constitui uma primeira resposta a um problema que não é acadêmico, mas remete a lutas políticas e sociais reais.

Croce e Gentile são postos por Gramsci em conexão com a Itália derivada do Risorgimento: contra eles se insurgem os ambientes "clericais" (Gramsci, 1980, p. 392) que, na Sardenha (e na Itália) da época, constituem uma força decisiva do conservadorismo pelo medo que estimulam em relação a qualquer mudança social, definida de antemão como um pavoroso salto no escuro (Fiori, 1966, p. 100). Esses ambientes con- 
sideram Hegel a sua "besta fera" (Gramsci, 1980, p. 392) e, junto à sua filosofia, buscam rechaçar o moderno. No entanto, "na luta entre o Syllabus e Hegel, foi Hegel quem venceu” (idem, ibid., p. 72). É a vitória não apenas de um filósofo, mas de um "desenvolvimento histórico" e de um mundo histórico real que encontrou sua expressão teórica no sistema do pensador alemão. É a vitória de um processo que, a partir da Reforma, comporta a destruição do feudalismo e do antigo regime, a afirmação da secularização (com "o bom velho deus, que volta ao reino das larvas"), o emergir da figura do indivíduo moderno que afirma o "livre arbítrio" e a "filosofia pura" sem o estorvo de uma autoridade externa (idem, ibid.). É, sobretudo, a vitória da consciência histórica que, dada a situação, se recusa a ver e a suportar uma natureza imodificável. A tomada de posição a favor de Hegel (e de Croce e Gentile) é, assim, uma tomada de posição a favor do moderno e, no que diz respeito à Itália, a favor do Risorgimento, que significou a derrocada do antigo regime, o advento de um Estado nacional moderno e a derrota de um Estado clerical claramente ainda pré-moderno (lembre-se o poder temporal do Papa, o caráter confessional das instituiçôes, o gueto para os judeus).

Tal como o encontro com Croce e Gentile, assim também a antítese Hegel-Syllabus não tem origem meramente especulativa. No documento pontifício, a condenação da liberdade de consciência e de expressão, da igualdade jurídica (com a supressão do "foro eclesiástico"), da obrigação escolástica e da escola pública, a condenação, em uma palavra, do mundo e da liberdade dos modernos, coincide simultaneamente com a denúncia da visão "do Estado como origem e fonte de todos os direitos”. O Syllabus não cita nomes; mas, alguns anos depois, o bispo Emmanuel von Ketteler ${ }^{2}$ é enfático: "Há muitos anos o liberalismo nos grita: tudo por obra do povo. Hegel nos diz: o povo, como o Estado, tem o poder absoluto sobre a terra. Com essa máxima combateu-se a autoridade que provém de Deus e escarneceu-se da nossa fórmula: pela graça de Deus" (Ketteler, 1871, apud Losurdo, 1997, cap. IV, p. 2). O eminente homem da igreja assim prossegue: "O liberalismo faz do Estado um Deus na terra", no sentido de que "não há nenhuma lei divina e eterna acima da lei do Estado". De modo análogo, ainda antes do Syllabus, argumenta na Itália Antonio Rosmini, a "moderna antropolatria”, que encontra sua expressão acabada em Hegel, desemboca na "estatolatria", no desejo de modificar o ordenamento político e social segundo o arbítrio do homem (Losurdo, 1997, cap. IV, p. 2). 
O Hegel do qual Gramsci se vale é o Hegel combatido pelo conservadorismo por ser liberal e moderno, expressão da consciência histórica, da possibilidade de mudança e da possível iniciativa transformadora do sujeito humano. Sua filosofia desempenhara um papel importante na preparação ideológica da revolução de 1848. Nesse quadro, deve-se também colocar a menção a Croce e Gentile, discípulos italianos do filósofo alemão, empenhados na defesa do Risorgimento. Mas isso marca, desde o início, o caráter problemático da relação de Gramsci com os dois grandes intelectuais laicos. Atribui-lhes um crédito, por assim dizer, sub judice: a leitura de seus textos destina-se à procura de uma resposta, ou de material para uma resposta a um problema real; e o valor de tal resposta continuará a ser medido pela contribuição que possa fornecer à compreensão e à solução dos problemas reais. Não surpreende, assim, o fato da posterior evolução levar Gramsci a considerar os dois grandes intelectuais neo-idealistas não mais como alferes da luta em defesa do moderno, mas como cúmplices do obscurantismo antimoderno de Pio X, empenhados, em nome da defesa do ordenamento social, em não afetar a influência da cultura clerical mais reacionária sobre as massas populares (idem, ibid., p. 3). Por outro lado, também o juízo sobre a cultura católica é sempre histórico e politicamente concreto. Um importante testemunho revela que o jovem Gramsci já condenava enfaticamente o "anticlericalismo estúpido" de quem não compreende a clara superioridade do pacifismo evangelicamente inspirado frente ao intervencionismo de determinados "ateus" declarados (Fiori, 1966, p. 123).

No que diz respeito aos dois filósofos neo-idealistas, eles são lidos como a expressão teórica do Risorgimento e de uma revolução "burguesa" que se trata de levar a termo (e, segundo uma visão que amadurece progressivamente, de completar e superar). Croce e Gentile são assim submetidos a uma interpretação na qual não se poderiam reconhecer. Quer dizer que, mesmo quando se sente mais próximo deles, Gramsci constrói essa relação de proximidade de tal modo que, aos olhos dos dois autores por ele interpretados, apareceria apenas como a confirmação de uma estranheza recíproca radical.

\section{Positivismo e neo-idealismo}

Mas, por que a luta pela modernidade e contra o imobilismo é conduzida tendo como referência os dois grandes filósofos neo-idealistas, 
muito mais do que a cultura oficial do Partido Socialista? O interesse e a admiração pelos dois grandes intelectuais da Itália após o Ressurgimento não estão em contradição com a posição empática em relação às classes subalternas? Mais tarde, Gramsci lembrará de uma frase de Camillo Prampolini: "A Itália se divide em nórdicos e su[di]jos" (Gramsci, 1971, p. 149). Turati não pensa de modo diferente. Ao identificar, também ele, o Sul com o atraso e a barbárie, lamenta a presença de "duas nações na nação, duas Itálias na Itália", e condena a "união forçada e antifisiológica do decrépito Sul com o severo Norte" (Monteleone, 1987, p. 284-285; Lepre, 1994, p. 83). A cultura do Partido Socialista da época não apenas não ajuda a resolver, mas também não compreende a questão meridional, sobre a qual faz uma leitura naturalista e até racial:

O Sul da Itália (Mezzogiorno) é a bola de chumbo que impede progressos mais rápidos em direção ao desenvolvimento civil da Itália; os meridionais são seres biologicamente inferiores, semibárbaros ou bárbaros completos, por destino natural; se o Mezzogiorno é atrasado, a culpa não é do sistema capitalista ou de qualquer outra causa histórica, mas da natureza, que fez os meridionais poltrôes, incapazes, criminosos, bárbaros (...). O Partido Socialista foi em grande parte o veículo desta ideologia burguesa no proletariado setentrional; o Partido Socialista crismou toda a literatura "meridionalista" da confraria de escritores da assim chamada escola positiva, como os Ferri, os Sergi, os Niceforo, os Orano e seguidores menos importantes, que, em artigos, em esboços, em novelas, em romances, em livros de impressões e memórias repetiam, de diversas formas, o mesmo refrão; mais uma vez a "ciência" era usada para esmagar os miseráveis e os explorados, mas, desta vez, vestida com as cores socialistas, pretendia ser a ciência do proletariado. (Gramsci, 1971, p. 140)

Essa ideologia já fora rejeitada pelo jovem estudante de liceu, partícipe do sofrimento de seu povo, e dos outros "povos infelizes", que não aceita ser estigmatizado como bárbaro e confinado entre os bárbaros e que, em um trabalho escolar, observou: "os privilégios e as diferenças sociais, sendo produto da sociedade e não da natureza, podem ser superados" (Fiori, 1966, p. 78). Com razão, Gramsci considera superior, no plano político, além de filosófico, a cultura neo-idealista que, ao enfrentar o problema do atraso do Mezzogiorno, apesar de não o vincular ao sistema capitalista, recusa-se a abandonar o terreno da história.

A cultura neo-idealista continua a demonstrar sua superioridade ainda por ocasião da I Guerra Mundial. Pode ser considerado exemplar 
o caso de Guglielmo Ferrero, colaborador da revista Critica Sociale e positivista, influenciado por Cesare Lombroso. Na passagem do século XIX para o XX, critica o governo central, atribuindo-lhe o desejo de "manter as regiōes ociosas à custa das regiōes trabalhadoras". Como a questão meridional na Itália, também a questão irlandesa na GrãBretanha é lida em chave antropológica: em confronto estão, de um lado, a "energia dominadora" e as outras "raras energias da raça anglo-saxă" e, de outro, um "caráter céltico" feito de "fáceis entusiasmos", "impaciência colérica" e "espírito indisciplinado e estranho à organização". Até para um caráter fanático e missionário como o de Francesco Crispi não parece estranho o "sangue albanês" que, se sussurra, "corre em suas veias" (Ferrero, 1895, pp. 78, 32 e 34).

Com os mesmos olhos com os quais vê a questão meridional italiana e a questão irlandesa, Ferrero vê, nos anos que precedem o primeiro conflito mundial, o contraste, em nível europeu e mundial, entre o prodigioso desenvolvimento das "raças germânicas" (os povos da Alemanha, da Inglaterra e dos Estados Unidos da América) e o imobilismo ou o atraso das "raças latinas [que] vivem à custa da riqueza acumulada no passado" (Ferrero, 1903, p. 417). Com o irromper da guerra, a dicotomia germanismo-latinidade continua a subsistir, mas é reinterpretada em chave anti-alemã e exclusivamente anti-alemã. E isso para caracterizar, junto ao Segundo Reich de Guilherme II, uma espécie de mítica Alemanha eterna. A sua expressão está concentrada na filosofia de Hegel, cuja difusão parece evocar as invasões bárbaras.

Quando o hegelianismo dos países setentrionais, aonde veio à luz, saiu pelo mundo e tentou transpor os confins do antigo Império de Roma, suscitou, com seu aparecimento, uma espécie de horror. Este abjeto sofisma, que confundia todos os critérios do bem e do mal a serviço de todos os arrivistas - fossem povos, Estados, classes, partidos e homens -, causou asco nos espíritos mais elevados, mais profundos e mais nobres dos países latinos. (Losurdo, 1997, p. 206)

Croce e Gentile zombaram desses paradigmas antropológicos (Losurdo, 1997). ${ }^{3}$ O liberalismo dos dois filósofos neo-idealistas, permeado de cultura histórica, revela-se superior a determinadas correntes do liberalismo anglo-saxão, inclinado também ele a naturalizar o conflito. Deixemos, por enquanto, o social-darwinismo de Spencer. Os estereótipos caros a Ferrero podem ser encontrados também em um au- 
tor como John Stuart Mill. Aos anglo-saxões, o liberal inglês contrapõe negativamente não apenas os bárbaros encerrados no "estado selvagem, ou quase" (que constituem "a grande maioria da raça humana"), mas também os povos do "Sul da Europa", cuja "indolência" e "inveja" impedem o desenvolvimento da sociedade industrial, a consolidação de um sólido grupo dirigente e o ordenado funcionamento das instituições. Até em relação aos outros povos que habitam o coração da Europa, os anglosaxões terminam por revelar-se superiores, privados como são daquelas características ("submissão", "resignação", estatismo) típicas dos franceses e das "naçôes continentais", todas "gangrenadas pela burocracia" e pelo invejoso frenesi igualitário (Mill, 1916, p. 61-4).

Da glória anglo-saxã não parece poder participar, naqueles anos, a Irlanda, em condições de grave atraso e vítima da brutal opressão britânica. Quando, no final do século XIX, uma personalidade de primeiro plano da cultura liberal da época, o historiador William Edward Hartpole Lecky, sugere ao governo de Londres uma política de conciliação com os irlandeses, a recomenda com base no argumento de que, apesar de tudo, também os irlandeses fazem parte da "grande raça ariana"! (Cannadine, 1983, p. 99). Não é essa, porém, a visão mais difundida que insiste, ao contrário, na estraneidade dos celtas irlandeses em relação à raça anglo-saxã ou "teutônica", que inclui também a Alemanha e os Estados Unidos. Em 1860, Lorde Robert Cecil (futuro Marquês de Salisbury e futuro Primeiro-Ministro da Grã-Bretanha) contrapõe "aos povos dos climas meridionais, aqueles de ascendência (...) teutônica”; em 1899, Joseph Chamberlain (Ministro das Colônias) chama oficialmente os Estados Unidos e a Alemanha para formar, com seu país, uma aliança "teutônica" (Kissinger, 1994, p. 186). E, como Ferrero, também a cultura liberal ou liberal-positivista inglesa não hesita, com o irromper da I Guerra Mundial, em recolocar, em função antialemã, os mesmos estereótipos. Não há dúvida: partindo de Croce e Gentile, Gramsci vale-se dos filósofos que, naquele momento, se colocavam entre os autores que exprimiam a mais avançada cultura européia e mundial.

Compreende-se, então, a dura crítica ao positivismo que, para Gramsci, é sinônimo de naturalização, sob diversas formas, do processo histórico. "Essencialmente positivista" é a visão da história da Action Française:

"A sociedade é, para Daudet e Maurras, como uma planta, a planta dos lírios de ouro da dinastia milenar dos reis de França; suas raízes afundam 
na alma particular do povo e da raça francesa". Estes "católicos e positivistas" constroem todo o seu discurso sobre "pseudoconceitos de raça, de região, de alma, de ordem, de hierarquia, de herança”. Para eles, "a 'Revolução' não é originária da França; depende da Reforma protestante”. (Gramsci, 1984, p. 347-348).

Se Mill considera as incessantes agitações revolucionárias da França como uma espécie de doença hereditária de um povo corroído pela inveja e anarcóide, a Action Française denuncia naquelas mesmas agitações uma doença provocada por um agente patogênico externo. Independentemente do juízo de valor diferente e contrário, é comum às duas posições a evasão do terreno da história e o recurso ao paradigma antropológico ou sublinha Gramsci com linguagem croceana - a "pseudoconceitos".

\section{Liberalismo e antijacobinismo}

Ao irromper da guerra, o estudante sardo e turinês não olha para Berlim ou para a posição assumida pelos líderes da Segunda Internacional, mas continua a voltar sua atenção, de modo privilegiado, para os dois filósofos neo-idealistas: Não tinham se oposto sempre à leitura naturalística dos conflitos? Não tinham contraposto constantemente a história aos estereótipos nacionais e ao paradigma antropológico? $\mathrm{O}$ que poderiam dizer de uma guerra apresentada pelos governos e por seus ideólogos como confronto entre almas nacionais irremediavelmente hostis? Na realidade, depois do artigo de 31 de outubro de 1914, no qual Gramsci procura se posicionar diante do debate no Partido Socialista, ${ }^{4}$ as sucessivas intervenções jornalísticas são por um bom tempo polêmicas, levando em conta as lições de Croce e Gentile, contra os círculos mais exaltadamente chauvinistas que pretendiam subordinar completamente a cultura à total mobilização bélica e considerar e celebrar a guerra como a cruzada de uma civilização superior contra uma civilização inferior ou, verdadeiramente, contra a barbárie.

Conclusão: partindo do Risorgimento e das polêmicas contra o Syllabus, reivindicando a modernidade atacada pelo documento pontifício e defendendo Hegel, condenado por ser moderno e liberal, fazendo constante referência a Croce e Gentile (naquele momento com posiçôes solidamente liberais), assumindo tais posições, Gramsci começa de alguma maneira como liberal. E isso não entra em contradição com o vivo interesse por Marx, cuja interpretação é mediada pela leitura dos dois filósofos neo- 
idealistas. A Achille Loria e seu fantasioso "marxismo" de feição positivista são contrapostos contemporaneamente "Antonio Labriola e Friedrich Engels e B. Croce" (Gramsci, 1980, p. 33).

À influência dos dois grandes intelectuais italianos, neo-idealistas e liberais, deve-se também a acepção negativa com a qual Gramsci inicialmente usa a palavra "jacobinismo". Duríssimo é o julgamento feito por ele, em junho de 1918, a esse movimento político caracterizado pela "incapacidade de compreender a história", por "uma visão messiânica da história", por um discurso totalmente construído sobre "abstrações", pela "pretensão política de suprimir violentamente qualquer oposição" (Gramsci, 1984, p. 148-149).

À Terceira República, que conseguira o sufrágio universal (masculino), o jovem Gramsci parece preferir não apenas os Estados Unidos da América (EUA), onde continua a campear a discriminação racial dos direitos políticos (e algumas vezes também dos civis), mas também a Inglaterra, onde a persistente restrição censitária ao sufrágio alia-se à presença de um antigo regime ainda sólido e vigoroso e à opressão da Irlanda. Eloqüente é o artigo publicado no Avanti! de julho de 1918:

A França que os democratas admiram é a França reacionária, é a França que fala e não age, é a França demagógica que destrói a Bastilha, mas não destrói as condiçōes das quais ressurgirá o despotismo (...). A França não é muito superior em média à Alemanha e à Itália. É um país com estrutura econômica e administrativa despótica. Um tirano, apossando-se de Paris, dominaria a França; porque toda a França depende de Paris. Mas, um tirano que se apossasse de Londres ou de Washington não dominaria a Inglaterra e os Estados Unidos, porque o capitalismo anglo-saxão, em seu desenvolvimento desordenado, se garantiu, com a descentralização, com a divisão clara dos poderes, contra qualquer tirania. (idem, ibid., p. 183)

A condenação da guerra não parece envolver totalmente o mundo liberal e anglo-saxão. Acusa-se, em uma série de intervenções em 1916, sobretudo o protecionismo, a "guerra econômica" preparada e alimentada pelo protecionismo, que destruiu o "liberalismo entre Estado e Estado" (Gramsci, 1980, p. 446). Ao reproduzir no Grido del Popolo um artigo "honesto e sério" de Luigi Einaudi contra o protecionismo (idem, ibid., p. 471), Gramsci declara-se de acordo com ele e outros autores liberais, que "crêem que o livre comércio, além de um problema econômico, seja também um problema moral. E, por isso, a palavra deles tem 
um significado universal, transcende os limites de classe" (idem, ibid., p. 497).

Certamente, pelo menos em parte, o "protecionismo", mais tarde, torna-se o "imperialismo". Mas, confirmando a forte influência da tradição liberal, faz, ainda em outubro de 1918, uma crítica entusiasta ao liberalismo-liberismo de Richard Cobden:

A propaganda do livre comércio teve caráter nobre e se coordenava com uma visão das relaçōes internacionais essencialmente pacíficas, de modo a criar, para a produção e o comércio, o ambiente mais oportuno e adequado para o máximo desenvolvimento, que ofereceria à humanidade os meios mecânicos para a consecução dos fins mais próprios à sua natureza. Cobden viajava pela Europa pregando o novo verbo, e a sua escola colocava na propaganda aquele entusiasmo puritano que é a base moral dos povos anglosaxões. (Gramsci, 1984, p. 315)

Nesse momento, as posições de Gramsci não parecem muito distantes das de Joseph Schumpeter, que, logo depois do fim do primeiro conflito mundial, colocava o belicismo e o flagelo da guerra na conta exclusiva do antigo regime, para ele encarnado pela Alemanha e pela Áustria. Desse modo, não apenas passa por alto sobre a vitalidade do antigo regime na própria Inglaterra, como não submete à categoria de guerra as expedições coloniais britânicas ou as repetidas intervenções militares norte-americanas no hemisfério ocidental (Losurdo, 1996, cap. IV, p. 3).

A Schumpeter (e, em parte, ao jovem Gramsci) se poderia contrapor o testemunho de Cobden, que faz, na metade do século XIX, este significativo balanço da política externa e militar de seu país:

Fomos a comunidade mais agressiva e combativa que jamais existiu desde a época do império romano. Depois da revolução de 1688, gastamos mil cento e cinqüenta milhões (de libras esterlinas) em guerras, nenhuma das quais combatida em nossas praias, ou em defesa de nossos lares e de nossas casas (...). Esta propensão guerreira sempre foi reconhecida, sem exceção, por todos aqueles que estudaram nosso caráter nacional. (Pick, 1994, p. 33)

Ou se poderia contrapor à teorização explícita da política do "grande bastão" por parte de uma América que assume a herança da GrãBretanha na cruzada pela "porta aberta" e o livre comércio, sem que isso a impeça de empenhar-se em uma série de guerras e de intervenções mi- 
litares, no hemisfério ocidental, contra a Espanha, e nas Filipinas, subtraídas à mesma Espanha...

Depois da queda da autocracia czarista na Rússia, enquanto Alexander Kerenski, atraindo a ironia de Lênin, se coloca como um jacobino que dirige a nação revolucionária em armas contra os exércitos invasores dos impérios centrais (Losurdo, 1996), Gramsci preocupa-se em defender a revolução de fevereiro da acusação de jacobinismo, "fenômeno puramente burguês" e, portanto, estranho a uma revoluçãa considerada, como veremos, "proletária" (Gramsci, 1982, p. 138-139).

Mesmo depois da Revolução de Outubro, Gramsci exprime-se calorosamente sobre Thomas Woodrow Wilson, positivamente contraposto ao primeiro ministro francês Georges Clemenceau, que não hesita em assumir poses jacobinas, mas que, na realidade, apesar de não poder ser confundido com o presidente norte-americano, "está próximo espiritualmente de Bethmann-Hollweg" (Gramsci, 1984, p. 184). O presidente norte-americano (que dirige um povo sem estorvos feudais nas costas e que, com a independência, conseguiu a "liberdade econômica e política" e a "libertação do indivíduo dos vínculos e das tutelas paternalistas dos monopolizadores da sabedoria e da justa medida") é comparado ao chefe da Rússia soviética: "Lênin e Wilson são os dois gênios políticos que a guerra colocou em primeiro plano, neles e em sua obra se fixa a atenção da melhor parte, respectivamente, do proletariado e da burguesia" (idem, ibid., p. 157-158).

\section{A revolução contra o Syllabus}

As profundas ligações com a mais avançada cultura liberal da época não impediram que Gramsci saudasse a Revolução de Outubro. $\mathrm{E}$ isto também porque o liberalismo do qual se vale tem características peculiares e singulares. Voltemos a Ketteler e à cultura católica dos anos do Syllabus e da polêmica anti-risorgimental. Depois da condenação, já citada, da filosofia hegeliana e do liberalismo que, ao repelirem a fórmula "pela graça de Deus", não reconheceram qualquer limite à iniciativa transformadora e legisladora do homem, do povo e do Estado, o eminente homem da igreja assim prosseguiu: "Se as premissas são verdadeiras, se o Estado é Deus na terra, se a lei é absoluta, quem pode contestar seu direito de reformar as leis que regulam a propriedade? $\mathrm{O}$ 
que ele fez como Deus, para falar a linguagem de Hegel, pode também refazer. O que era justo a primeira vez, deverá sê-lo uma segunda” (Losurdo, 1997, p. 126).

Ainda segundo Rosmini, a "moderna antropolatria" se amplia em "estatolatria”, que por sua vez fundamenta a pretensão socialista de legitimamente realizar uma redistribuição da riqueza e da renda (Losurdo, 1997, cap. IV, p. 2). Visto como sinônimo de uma modernidade que pretende substituir as eternas leis naturais e divinas pela iniciativa histórica do homem, o liberalismo, condenado pela cultura católica da época, desde o início carrega dentro de si o socialismo.

Vejamos agora como argumenta Gramsci a partir de outubro de 1917. Pouco mais de um ano antes, se empenhara em uma polêmica com os católicos que, pela paz, rezam à Nossa Senhora e "invocam a boa vontade dos santos, quando seria mais oportuno apelar pela dos homens". Tal posição de resignação significa uma recusa ou o desconhecimento da modernidade: "Apenas o que é obra, conquista nossa, tem valor para nós, torna-se parte de nós mesmos, não o que vem dado generosamente por um poder superior, seja ele o Estado burguês, ou Nossa Senhora da Consolação" (Gramsci, 1980, p. 392-393). Nesse sentido, "nossa religião volta a ser a história, nossa fé volta a ser o homem e sua vontade ativa (...). E assim nos sentimos inevitavelmente em oposição ao catolicismo e nos dizemos modernos" (idem, ibid., p. 514). Em julho de 1918, ao rechaçar a campanha desencadeada contra a Revolução de Outubro, Gramsci escreve que "quem considera Lênin um utópico (...) é um católico, viceja no pântano do Syllabus" (idem, 1984, p. 208-209). O mote de dois anos antes, Hegel contra $o$ Syllabus, assume, então, uma nova configuração: Lênin contra o Syllabus! Quem continua a recomendar a submissão das massas aos Estados burgueses, que as imolam como vítimas sacrificadas sobre o altar da guerra, está impregnado de metafísica e teologismo, está aquém da modernidade em seu sentido mais elevado e mais forte. Através de etapas sucessivas, e através de um processo complexo e contraditório, a modernidade configura-se como uma gigantesca revolução contra o Syllabus. É uma revolução que vê a afirmação da subjetividade livre, e esta subjetividade livre afirma-se plenamente na luta contra a presumida fatalidade da guerra e de seu rito de sacrifício.

A revolução bolchevique é então vivida como uma conseqüente aplicação dos princípios liberais. Junto a uma ruptura, comporta tam- 
bém elementos de continuidade. O mesmo artigo de outubro de 1918, que elogia Cobden como apóstolo do "livre comércio", afirma que "a idéia da Internacional amadureceu criticamente no pensamento de Marx", precisamente "naquele período da história inglesa". A elaboração teórica e política de Marx não é uma criação ex nibil; ele "elaborou criticamente estas tendências da civilização capitalista, reconheceu que eram essenciais à história e construiu a ideologia da Internacional operária”. O próprio Wilson exprime "uma civilização que, para os socialistas, representa o pressuposto de seu triunfo" (Gramsci, 1984, p. 315).

Não falta ingenuidade nessa visão, que tende a transfigurar a história do liberalismo real e parece subestimar a aspereza do conflito já aberto entre a Rússia soviética e o movimento comunista, de um lado, e o Ocidente capitalista, aí incluído seu componente liberal, do outro. Claramente, o problema da herança necessita de posterior precisão, capaz de ajudar a recolher e enquadrar, junto às linhas de continuidade e de desenvolvimento na continuidade do processo histórico de emancipação, também os dramáticos conflitos que o caracterizam. Porém, um ponto já está decidido: o comunismo pode ser entendido apenas como realização da modernidade. É apenas nesse sentido que se pode falar de "socialismo crítico" (Gramsci, 1980, p. 392) ou de "comunismo crítico" (Gramsci, 1984, p. 348).

A adesão à revolução desencadeada contra o Syllabus não comporta uma imediata ruptura com Croce e Gentile. Gramsci nutre a esperança e a ilusão de poder proceder, com a filosofia deles, do mesmo modo que Marx e Engels procederam em relação à filosofia clássica alemã: herdando-a e incorporando-a. Trata-se de realizar uma Aufhebung, uma superação que, longe de ser sinônimo de liquidação sumária, implica, como momento essencial, a assunção de uma herança.

A Itália é o país no qual exerce a mais ampla e mais duradoura influência sobre o movimento operário e comunista a tese (que atravessa profundamente a obra de Marx e Engels e encontra sua formulação mais clássica no Ludwig Feuerbach e o fim da filosofia clássica alemã, publicado por Engels em 1888) segundo a qual "o proletariado é o herdeiro da filosofia clássica alemã” (Marx \& Engels, 1955, p. 307). Na França do final do século XIX, o próprio genro de Marx, Paul Lafargue, considera Kant um simples "sofista burguês" (Mehring, 1961, v. XIII, p. 39). Na Alemanha de 1870, Wilhelm Liebknecht, um dos dirigen- 
tes mais famosos da social-democracia alemã, ao publicar em uma revista do partido um artigo de Engels que cita Hegel, considera oportuno colocar esta nota de redação: "conhecido pelo grande público como o descobridor e o apologista da idéia régio-prussiana de Estado!”. Ao que Engels reagiu com extrema violência: "Este animal se permite estampar, no pé de meu artigo e sem assinar, notas que são verdadeiras tolices (...). Este ignorante tem a desfaçatez de querer liquidar um tipo como Hegel com a palavra prussiano". E também a reação de Marx, que endereça uma dura carta de protesto a Liebknecht (Marx \& Engels, 1955, p. 501 e 503), ${ }^{5}$ é igual à de Engels. No entanto, as coisas não parecem mudar substancialmente na social-democracia alemã. Assim, no mesmo ano de 1888, no qual Engels publicou seu Feuerbach, pelas colunas da revista Die neue Zeit, Karl Kautsky formula uma crítica bastante severa, de substancial liquidação da filosofia clássica alemã:

A revolução teórica da Inglaterra e da França foi o resultado da necessidade continuamente crescente, por parte da burguesia, de uma revolução econômica e política (...). A revolução teórica da Alemanha foi o produto de idéias importadas; "teorias" "essencialmente materialistas" na França e na Inglaterra assumem na terra alemã a forma do "idealismo filosófico". (Kautsky, 1888, VI, p. 76)

Como se vê, ao atraso econômico e político corresponde plenamente também o atraso ideológico da Alemanha: não há lugar para a desigualdade do desenvolvimento, e o idealismo alemão dificilmente pode constituir um ponto de referência ou uma herança a ser reivindicada.

Aproximadamente na mesma época, ao fazer o balanço filosófico e político de sua vida, Antonio Labriola escreve em uma carta: "Talvez - até sem talvez - eu tenha me tornado comunista devido à minha educação (rigorosamente) hegeliana", graças ao encontro juvenil com o "reflorescimento napolitano do hegelianismo", que tem por protagonistas os irmãos Spaventa (Bertrando e Silvio). Significativamente, o destinatário dessa carta é Engels, e Antonio Labriola demonstra conhecer bem o autor de Ludwig Feuerbach e compartilhar plenamente a tese segundo a qual o proletariado é o herdeiro da filosofia clássica alemã (Losurdo, 1997). Esta tese desempenha um papel importante na formação do grupo dirigente de L'Ordine Nuovo. Escrevendo na revista dirigida por Gramsci, Togliatti declara, dois anos depois da Revolução de Outubro, que "Marx é filho direto de Hegel" (Togliatti, 1973, v. I, 
p. 66). E em 1925: "Ao marxismo pode-se chegar por diversas vias. Nós chegamos pela via seguida por Karl Marx, isto é, partindo da filosofia idealista alemã, de Hegel (...). No que nos diz respeito, a via que seguimos é, com relação a qualquer outra, a via mestra, e como tal tem todas as vantagens". É a via - acrescenta Togliatti - indicada, e pela primeira vez seguida, na Itália, por Antonio Labriola, que depois desgraçadamente a abandonou em favor do assim chamado "positivismo científico" que, na realidade, não é outra coisa senão uma vulgar metafísica da história vista como mera necessidade natural (Togliatti, 1925, v. I, p. 648).

Gramsci talvez seja ainda mais radical: "a filosofia da práxis é uma reforma e um desenvolvimento do hegelianismo" (Gramsci, 1975, p. 1.487-1.489). Herdar a filosofia clássica alemã, que culmina em Hegel, significa, para o movimento operário e comunista, assumir não apenas a herança de uma simples manifestação filosófica, mas de uma expressão filosófica de extraordinária importância, que comportou a elaboração de categorias teóricas (contradição objetiva, salto qualitativo, dialética etc.) decisivas para a compreensão do processo revolucionário; trata-se de herdar o mundo histórico da modernidade.

Reside aqui o fascínio de uma evolução e de uma biografia intelectual que, a partir de dramáticos acontecimentos históricos (o primeiro conflito mundial, a revolução e a eclosão da primeira etapa da guerra, fria e quente, contra a Rússia soviética, o processo de radicalização ideológica e política do movimento operário no Ocidente, o despertar dos povos coloniais e as persistentes ambições imperialistas das grandes potências liberais, o advento do fascismo), aprofunda e radicaliza a crítica ao liberalismo e amadurece, em todos os níveis, a passagem ao comunismo. Porém, a um comunismo que nunca perde a consciência do problema da herança. Nesse sentido, se poderia e se deveria escrever, com relação a Gramsci (e Togliatti), algo análogo a um célebre livro dedicado a Marx e Engels do liberalismo ao comunismo (Cornu, 1955, p. 1.818 e $1.820-1.844){ }^{6}$

É ainda mais fascinante essa evolução do liberalismo para o "comunismo crítico", pelo fato de ser um contraponto objetivo à evolução de não poucos intelectuais que, ante os mesmos acontecimentos, e a partir do mesmo desafio histórico, empreenderam uma marcha de aproximação com o fascismo, ou aderindo (foi o caso de Gentile), ou che- 
gando à beira da adesão, ou ainda participando da elaboração de temas e motivos ideológicos sucessivamente herdados pelo fascismo.

Recebido em fevereiro de 2006 e aprovado em abril de 2006.

\section{Notas}

1. Mas está redimensionada a afirmação segundo a qual "em todos os escritos juvenis Gramsci cita Labriola apenas uma vez" (em 1918!).

2. Nota da Org.: Trata-se do nobre e bispo de Mogúncia, barão Wilheim Emmanuel Freiherr von Ketteler (1811-1877), que foi deputado do parlamento alemão, inspirador do partido de centro e do sindicalismo católico alemão. Fez célebres sermões sobre a "questão social", como A questão operária e o cristianismo (1864) e Liberalismo, socialismo, cristianismo (1871).

3. A essa obra (Losurdo 1997, caps. 3-4) remetemos também o leitor para acompanhar a sucessiva involução de Gentile, que levará o filósofo a aceitar os estereótipos nacionais anteriormente refutados e a aderir ao fascismo.

4. Trata-se de uma tomada de posição cautelosa e problematicamente favorável ao pronunciamento de Mussolini em favor da passagem do Partido Socialista da "neutralidade absoluta" à "neutralidade ativa e operante" (Gramsci, 1980, p. 10-14). Líder da ala revolucionária, Mussolini apressa-se em percorrer a estrada do intervencionismo. Compreende-se agora a leitura, corretamente definida como "sectária", intervencionista, do artigo de Gramsci (Fiori, 1966, p. 113). Porém, à luz das sucessivas intervenções e dos sucessivos silêncios de Gramsci, parece problemática também a leitura leninista do artigo em questão, como uma espécie de adesão objetiva à palavra de ordem de transformação da guerra imperialista em guerra civil revolucionária (Giacomini, 1975, p. 15-19; Taboni, 1975, p. 119-187).

5. Sobre isto chamou a atenção Weil (1988, p. 67).

6. Nas páginas seguintes, Gramsci e Togliatti aparecem freqüentemente próximos. Sua contraposição é um mito político, mais do que historiográfico, como demonstra Canfora (1997) de modo eficaz e brilhante.

\section{Referências bibliográficas}

CANFORA, L. Chi ha paura di Togliatti? Milano: Teti, 1997.

CANNADINE, D. Il contesto, la rappresentazione e il significato del rito: la monarchia britannica e l'invenzione della tradizione. In: Hobsbawn, E.J.; Ranger, T. (Org.). L'invenzione della tradizione. Turim: Einaudi, 1987. p. 99-159 (ed. orig. 1983).

CORNU, A. Karl Marx et Friedrich Engels: leur vie et leur œuvre. Paris: PUF, 1955. 4v. 
CORNU, A. Marx e Engels dal liberalismo al comunismo. Trad. de F. Cognetti e M. Montinari. Milano: Feltrinelli, 1962.

FERRERO, G. La reazione (1894). 2. ed. Turim: Olivetti, 1895.

FERRERO, G. L'Europa giovane: studi e viaggi nei paesi del Nord. Milano: Treves, 1903.

FIORI, G. Vita di Antonio Gramsci. Bari: Laterza, 1966.

GIACOMINI, R. Gramsci e la formazione del Partito Comunista d'Italia. Napoli: Cultura Operaia, 1975.

GRAMSCI, A. Socialismo e fascismo. (L'Ordine Nuovo: 1921-1922). Turim: Einaudi, 1966.

GRAMSCI, A. La costruzione del partito comunista: 1923-1926. Turim: Einaudi, 1971.

GRAMSCI, A. Quaderni del carcere. Turim: Einaudi, 1977.

GRAMSCI, A. Cronache torinesi: 1913-1917. Turim: Einaudi, 1980.

GRAMSCI, A. La città futura: 1917-1918. Turim: Einaudi, 1982.

GRAMSCI, A. Il nostro Marx: 1918. Turim: Einaudi, 1984.

GRAMSCI, A. L'Ordine Nuovo: 1919-1920. Turim: Einaudi, 1987.

KAUTSKY, K. Arthur Schopenhauer. Die neue Zeit, v. 6, 1888.

KISSINGER, H. Diplomacy. New York: Simon \& Schuster, 1994. p. 186.

LECKY, W.E.H. A history of England in the eighteenth century. 3. ed. London: Longmans-Green, 1883-88. v. 2.

LÊNIN, V.I. Opere complete. Roma: Riuniti, 1955.

LEPRE, A. Italia addio?: unità e disunità dal 1860 a oggi. Milano: Mondadori, 1994.

LOSURDO, D. Il revisionismo storico: problemi e miti. Roma-Bari: Laterza, 1996. 
LOSURDO, D. Dai fratelli Spaventa a Gramsci: per una storia politico-sociale della fortuna di Hegel in Italia. Napoli: La Città del Sole [Instituto Italiano para os Estudos Filosóficos], 1997.

MARX, K.; ENGELS, F. Werke. Berlim: Dietz, 1955.

MARX, K.; ENGELS, F. Marx-Engels Gesamtausgabe. In: MarX, K.; Engels, F. India, Cina, Russia: le premesse per tre rivoluzioni (1960). Milano: Il Saggiatore, 1975.

MEHRING, F. Zur klassischen idealistischern deutschen Philosophie Immanuel Kant (1904). In: MeHring, F. Gesammelte Schriften. Berlim: Dietz, 1961. v. 13.

MILL, J.S. Considerations on representative government. London: Parker, 1861. (Trad. italiana: Mill, J.S. Considerazioni sul Governo rappresentativo. Milano: Bompiani, 1916 (passim).

MONTELEONE, R. Filippo Turati. Turim: utet, 1987.

PICK, D. War machine: the rationalization of slaughter in the modern age. New Haven: Yale University, 1993. (Trad. italiana: Pick, D. La guerra nella cultura contemporanea. Roma: Laterza, 1994).

SALVEMINI, G. Liberalismo e socialismo. (L'Unità, Firenze, 14 out. 1920). In: Salvemini, G. Opere. Milano: Feltrinelli, 1964-1978. v.8.

TABONI, P. La gramsciana neutralità attiva ed operante. Differenze, Urbino, n. 10, p. 119-87, 1979.

TOGLIATTI, P. Che cos'è il liberalismo? (L'Ordine Nuovo, Torino, 20-27 set.1919). In: Togliatti, P. Opere. Roma: Riuniti, 1973.

TOGLIATTI, P. La nostra ideologia. (L'Unità, Roma, 23 set. 1925). In: Togliatti, P. Opere. Roma: Riuniti, 1973. v.1.

WEIL, E. Hegel et l'État (1950). In: Burgio, A (Org.). Hegel e lo Stato e altri scritti hegeliani. Milano: Guerini, 1988. 